\title{
Role of multiple substrates (spent mushroom compost, ochre, steel slag, and limestone) in passive remediation of metal-containing acid mine drainage
}

\begin{abstract}
The potential of selected materials in treating metal-rich acid mine drainage (AMD) has been investigated in a series of batch experiment. The efficiencies of both single and mixed substrates in AMD treatment under two conditions i.e. low and high concentration solutions containing heavy metals were evaluated. Synthetic metal-containing AMD was used in the experiments treated using spent mushroom compost (SMC), ochre, steel slag (SS) and limestone. Different ratios of treatment materials were incorporated in the substrate mix and were tested for AMD treatment in an anoxic condition. In the batch test, physicochemical parameters ( $\mathrm{pH}$, redox potential, total dissolved solids, conductivity, Ca concentration) and heavy metals ( $\mathrm{Fe}, \mathrm{Mn}, \mathrm{Pb}, \mathrm{Zn}$, and $\mathrm{Al}$ ) were analysed. Overall, the mixed substrates have shown satisfactory performance in increasing $\mathrm{pH}$ with increasing $\mathrm{Ca}$ concentration and removing metals. It has been found that SS and ochre played an important role in the treatment of AMD in this study. The results showed that the mixed substrates SM1 (i.e. 10\% SMC mixed with $20 \%$ ochre, $30 \%$ steel slag and $40 \%$ limestone) and SM2 (i.e. $20 \%$ SMC mixed with $30 \%$ ochre, $40 \%$ steel slag and $10 \%$ limestone) were effective in increasing the $\mathrm{pH}$ from as low as 3.5 to 8.09 , and removing heavy metals with more than $90 \%$ removal efficiencies.
\end{abstract}

Keyword: Passive remediation; Acid mine drainage; Heavy metal; Limestone; Ochre; Spent mushroom compost; Steel slag 